\title{
The Importance of Holistic Approaches to the Patient in the 21st Century Medicine (Ars curandi - art of healing)
}

Z. Mojzesova (Zuzana Mojzesova), M. Mojzes (Marcel Mojzes)

${ }^{1}$ General practitioner ambulance for adults, Presov, Slovakia

Original Article

${ }^{2}$ University of Presov, Greek-Catholic Theological Faculty, Presov, Slovakia

\section{E-mail address:}

marcel.mojzes@unipo.sk

\section{Reprint address:}

Marcel Mojzes

University of Presov, Greek-Catholic Theological Faculty

Ul. Biskupa Gojdica

08001 Presov

Slovakia

Source: Clinical Social Work and Health Intervention

Volume: 9

Issue: 4

Pages: $84-89$

Cited references: 0

\section{Reviewers:}

Germano Marani

Pontifical Oriental Institute and Potifical Gregorian University, Rome, Italy

Steve Szydlowski

University of Scranton School of education, USA

\section{Key words:}

Holistic Approaches. 21 ${ }^{\text {st }}$ Century. Medicine and Patient.

\section{Publisher:}

International Society of Applied Preventive Medicine i-gap

CSWHI 2018; 9(4): 84 - 89; DOI 10.22359/cswhi_9_4_15 @ 2018 Clinical Social Work and Health Intervention

\section{Abstract:}

This paper is based on the empirical experience of the general practitioner/primary carer, but the principles of practice have been described in the last decades in many articles and monographs. It may be seen that the presented subject is highly current, not only theoretical but with the necessity of implementation in practice. In addition to familiar terminology, we present some new terms and key words that describe the situation in practice: fragmentation of medical knowledge; 
holistic approach; patient reduction; eternal patient; PC doctor; gnostic approach; accepting physician vs. direct approach. In the end, we ask a few questions, and their response in favor of a patient and medicine appears to be a priority.

\section{Holistic Approach to the Patient}

Medicine in the $21^{\text {st }}$ Century suffers from the fragmentation of medical knowledge and so the situation is that even the patient is fragmented: no longer on organ systems but on individual organs or even on parts of organs. This situation is progressing. The drug for a given condition is an holistic approach to the patient, and hence to integrate a fragmented patient.

Part of an holistic approach to the patient (certainly not exhaustive) is the reconciliation of physical, mental, social, spiritual status of patient and a question of time. If one of these modalities is omitted, the patient will still not feel comfortable, and we will not be able to talk about the treatment, but only about the symptomatic partial solution.

Another worthy question is associated with the sentence salus aegroti suprema lex - the patient's health is the highest law. What does health mean? What is the goal of a doctor? Is it possible to define the concept of health?

For example, an 86-year-old patient with coxarthrosis of the fourth degree, with severe hypacusis, walks with the care of his nurse and encourages younger and healthier friends to move more.

Or an 80-year-old patient with a few years of infaust disease - stomach cancer with a breakthrough in the environment, after resection of the stomach and a large part of the intestine with MTS diffusely is full of enthusiasm; he thanks for every care, is communicative and looks forward to the future.

In contrast, young patients, for example, with dyspeptic difficulties that are neither health-threatening nor life-threatening, are of functional origin but subjectively experienced as severe. Who is healthy and who is sick? Even young people are patients in true sense of the word because they lack something.

In practice, we see that the notion of health as defined by the WHO as a feeling of complete mental, physical and social well-being is inapplicable. It is reached almost by nobody. However, is this the goal? Wanting a patient to embrace this definition can be frustrating for both patient and Doctor.

We can see, therefore, that a different approach, like holistic, but which displaces medicine into ars curandi - a healing art, cannot be used either. Art, however, is beyond the scope of financial evaluation. At a time when everything can be bought, manufactured, obtained, it may be for the patient unexpected to get something extra: we could call it the principle of access. For patients who do not have the opportunity to fulfill the WHO definition of full health, this "something extra" can be the drug they benefit from. It is this "extra" that becomes the principle - the art that heals.

\section{Social Aspect}

The social status of the patient takes into account the environment as documented, for example, in a hygienic hypothesis. In general, a significant increase in allergic or atopic diseases in the industrialized world occurred between the 1960s and 1970s with growth progressions during the 1980s and 1990s. Prevalence in developing countries was $2-3 \%$, on the other hand $20-40 \%$ in 
developed countries. The rapid transformation of the environment and lifestyle did not allow the human immune system to adapt to these changes and reduced exposure to childhood illnesses indicates that it has contributed to an increased occurrence of incidence and prevalence of autoimmune and allergic diseases.

However, the financial solvency of the patient is also significant. We know that patients do not even take a drug they cannot afford. In some cases, it is necessary to cooperate with the environment, especially with the patient's family when mnestic functions are altered or other more severe disabilities are involved. A young newly diagnosed schizophrenic patient after her second hospitalization had to be integrated into a therapy group. However, the group she attended was cancelled. Mother suffers from severe depression; she is disabled with a cardiac rhythm disorder so has a permanent pacemaker implant. In the household she lives with a husband who is almost immobile and in the past had tortured the family. The daughter was sexually abused by her father; the son in adolescence was repeatedly prosecuted; two other children are problematic. Mother does not have energy to look for a new therapy group for her daughter so we took care of the search at our ambulance and informed the mother and the patient about possibilities.

\section{Mental aspect}

The mental aspect of the overall approach involves patient compliance: verbal intervention is often required; the patient much better accepts medication when she/ he is properly instructed with its benefits explained.

We do not underestimate pharmacological or other professional attitudes, and erudite health assessment always has a priority role. But often, we count on a few encouraging words with an understanding as an additional drug to the combination in addition without interactions with pills. A middle-aged woman after a particularly serious tentamen suicidii suffered with bipolar disorder. Then her 20 year-old daughter suffered from leukemia and after bone marrow transplant died. Subsequently, after the daughter's death, the patient's husband had a bladder cancer and is post-mortem. At that time, an undiagnosed disorder was found in her 6 years old granddaughter: her face deformed and she had to undergo dozens of corrective operations. Even though she lives in another town, this woman has built trust in some Doctors including us and has regular prescription drugs. Here, just inserting a prescription without verbal intervention would be a neglect of the duty. An important role is played in the relationship between Doctor and patient. The concept of a Family Doctor who recognizes generations and has the ability to create confidence in the course of continuous care is coming into the foreground.

It is important for the doctor to trust the treatment and prescribe it congruently - according to his conviction. With the need to use electronic media, a new phenomenon arises - a "doctor hidden within a PC"; the computer becomes a barrier; eye contact disappears; the interview is structured according to the computer diagrams.

In primary care, we often encounter incomplete patient awareness from specialist outpatient clinics. For example, an educated, assertive lawyer, overworked, frustrated by having to take care of children because of her husband's absence had several times changed jobs; had SVT paroxysms solved by radio-frequency ablation. She was anxiously tuned, but ambitious and very active. Recently, she suffered from polymorphic difficulties, repeatedly on APS (urgent ambulance or emergency first aid) given anxiolytics venous. She has been overly 
repeatedly treated by specialists, but no one has ordered her to undergo psychotherapy, nor teach her about the psychosomatic etiology of her difficulties. An holistic approach in this case presupposes knowledge of the patient's situation; courage to inform her fully and with tact; willingness of the Doctor to take antagonism. The first response of the patient was: "I'm normal! I do not need psychotherapy!" After the interview, she admitted a visit to the psychotherapist. If the patient, despite indications leading to the necessity of psychotherapeutic intervention, which is still perceived as stigmatizing in Slovakia, is repeatedly treated in specialized outpatient clinics the patient becomes chronic and frustrated and the so called "eternal patient" is formed.

Poor or incomplete information from patient outpatient clinics undermines the Doctor of first contact. A patient with a nephrotic syndrome who was diagnosed postpartum at our clinic, while at least one or two specialists overlooked her difficulties during and postpartum. She was informed by a nephrologist that if she wished to attend a lecture before starting treatment, with the argument that dialysis centers are all over the country, she could. It has been a great deal of effort to convince the patient and her husband that she is seriously threatened, that, even in histological and laboratory findings, her condition is so serious that she needs to avoid a group of people and tostart treatment immediately.

A patient with overturned and recurrent phlebothrombosis was repeatedly reminded by phone that his INR values were insufficient and hence should be promptly present to initiate concomitant therapy by LMWH and oral coagulants and to repeat the blood taking again. The patient vehemently argued that hematology, even if he had bad values, never had been a problem for him.

On the contrary, we appreciate the collegiality of cardiologists, internists and other specialists who are collegiate, accept our opinion and cooperate for the benefit of the patient. A 50-year-old woman appeared in our ambulance visibly exhausted, indicating palpitations that started when climbing the stairs. In the auscultation, tachycardia was diagnosed, instantaneous ECG was detected in our ambulance where SVT paroxysm was detected at a frequency of $120 / \mathrm{min}$; subsequently she had a sinus rhythm at a frequency of $70 / \mathrm{min}$. The cardiologist promptly responded by telephone intervention, examined the patient with our ECG and recommended RFA in a specialized ambulance.

For more complicated and untreatable conditions, the physician must manage his own therapeutic frustration. There are a large number of patients who suffer from polymorphic pains with only temporary relief, although it is stated that any pain should be treated in practice it is often not possible. For example, patients have polyvalent allergy to analgesics or gastric complaints, do not tolerate treatment of higher grade by analgesic patches as they have drug interactions and so on. At that time, word support is often helpful for the patient at least looking for a "new" solution; making sure he can come anytime.

In medicine today an "gnostic" principle dominates. Doctors heal only on the basis of knowledge and forget that there is an holistic principle - the art of healing. As the patient's personality goes beyond schematics, statistics and knowledge, structures that reduce him to numbers, we meet with reduced thinking and a "reduced patient" while the rule says that the person is always more than a prejudiced and learned scheme.

\section{Physical aspect, spiritual aspect, and the question of time}

The physical aspect of the holistic approach is perhaps the most commonly used it being the "daily bread" of doctors, i.e. 
erudition of a doctor at the level of knowledge and skills (of course, besides knowledge, relational competence is also necessary, etc.). However, using only this last option makes doctors craftsmen.

The spiritual dimension, for example, in the field of reproductive medicine, attempts to maintain fertility in women who wish to have more children than is generally considered "normal". Often curettage is proposed in the early stages of pregnancy with the fetuses often ejecting themselves or after medication. A physician who does not need to share a similar belief as a patient can become "accepting", not directive, and accessing the patient's wishes until her health is compromised.

We have experience with a case of a woman who, by accepting access to spontaneous abortion in the $1^{\text {st }}$ trimester, did not undergo curettage; she cleansed spontaneously and later has multiple family. On the contrary, we have experience with a woman who is almost on the edge of a fertile period after 40; she repeatedly underwent curettage 6 times until the immunological cause of the inability to become pregnant was detected. Today she undergoes treatment with the expectation of pregnancy.

Or a woman with a mild coagulation disorder in the sense of thrombophilia was proposed to be sterilized after the second child which she did not accept and has 4 healthy children without complications.

Knowing to have an accepting approach, considering a reasonable consideration of patient needs and requirements, requires the doctor's erudition as well as generosity. It seems like time has worked against us. An holistic approach is extremely demanding, but there are a lot of patients. However, the correct use of the above-mentioned eruditions that lead to holistic approaches can only be used within rationally defined time, not under its pressure.

\section{Discussion}

One paper cannot fully embrace holistic approaches to patients which opens up further questions arising from the continuous care of people whose needs are constantly changing. Currently, depersonalization is present in Slovakia in connection with the application of some new laws (e.g. the Privacy Act). The open question is, for example, how to apply this law so that the person will not be devalued. Similarly care for sick, handicapped, immobile patients remains a question that we have not been dealing with. A very special category is socially disadvantaged citizens - casus socialis, who are marginalized in normal outpatient clinics and so there are often no possibilities for doctors to treat them fully. This issue would merit a series of papers and discussion by a wider professional public, welcoming patients' insights to correct the paternalist approach of a doctor to the patient that has long been sustained in our society.

Finally, questions arise whether the WHO definition of health is achievable or is it a frustrating ideal? Is it necessary to meet requirements to make the patient feel good? Is it possible to define health without an holistic view of the person? There is a large group of patients who despite complex efforts remain ill. How to watch the disease? We add in this discussion words of French writer G. Flaubert: "Pearl is an oyster disease and yet something extremely rare. Pain is like self-improvement, it is more intense and full of insight into our soul and reality. "

\section{Conclusion}

As a result of fragmentation of medical knowledge, patient fragmentation occurs. The drug is an holistic approach to the patient which is the art of healing - ars curandi. An holistic approach has several aspects, such as: social, mental, physical, spiritual, the question of time. The WHO definition 
of health is in practice inoperable and limiting. Health is a highly subjective hardly standardizing concept. The doctor may be accepting or directing. He can treat patients with reduction and gnostically or generously. As a result of reduced access a "reduced patient" arises. Due to incomplete information, because it is in some cases more convenient, an "eternal patient" is repeatedly treated in specialist outpatient clinics. The doctor can try to establish eye contact and human contact or hide behind a PC. Time is a rare commodity and often forces doctors to restrict themselves to craft performance without an overall assessment of the patient's condition. The patient is more than numbers, statistics and knowledge - this great variability resulting from the uniqueness of a human being who cannot be embedded in numbers can lead to therapeutic frustration that the doctor cannot tolerate. 